\title{
Brachial Plexus Block For Upper Limb Surgery Coracoid Infraclavicular Approach versus Axillary Approach- A Comparitive Study
}

\author{
Parvez Akhtar', Supratim Dasgupta ${ }^{2}$, Priyadershini Rangari ${ }^{3}$ \\ ${ }^{1,2}$ Assistant Professor, Department of Anaeshtesiology, Sri Shankaracharya Medical College, Bhilai, Durg, Chhattisgarh, ${ }^{3}$ Assistant Professor, Department \\ Of Dentistry, Sri Shankaracharya Medical College, Bhilai, Durg, Chhattisgarh.
}

\section{Abstract}

Background: Peripheral nerve blocks (PNBs) have an increasingly important role in ambulatory anesthesia and have many characteristics of the ideal outpatient surgical anesthesia with prolonged postoperative analgesia, and facilitated discharge. Objectives: The aim of our study is to compare brachial plexus block performed by the Axillary and the Coracoid infraclavicular routes using a peripheral nerve stimulator as regard block performance time, onset of sensory block, motor block intensity, block duration and success and failure rates. Subjects and Methods: Our study comprised 40 adult patients of either sex t divided into two groups each 20 patients: Coracoid group and Axillary group were included. A $40 \mathrm{ml}$ mixture of equal parts of $0.5 \%$ bupivacaine and $2 \%$ lidocaine was used as the local anesthetic material for all the patients of both groups. Results: The axillary approach to the brachial plexus using four injections of the local anesthetic material resulted in a faster onset and fewer incomplete blocks than the coracoid approach using two injections. The axillary approach was also less painful and more comfortable to the patient and resulted in more intense motor block and provided a longer duration of block allowing for longer duration of anesthesia and postoperative analgesia. The coracoid approach had an advantage over the axillary that it can be done with the arm in the neutral position, which is important for patients with an arthritic or stiff shoulder joint. Conclusion: The axillary approach to the brachial plexus using four injections technique resulted in a faster onset of block and a better spread of analgesia and longer duration of anesthesia than the coracoid approach using two injections technique.

Keywords: Axillary Approach, Brachial Plexus, Bupivacaine, Coracoid Approach, Flexion, Lidocaine.

Corresponding Author: Dr. Supratim Dasgupta, Assistant Professor, Department of Anaeshtesiology, Sri Shankaracharya Medical College, Bhilai, Durg, Chhattisgarh.

Received: December 2019

Accepted: December 2019

\section{Introduction}

Techniques of peripheral neural blockade were developed early in the history of anesthesia. The american surgeons Halsted and Hall described injection of cocaine into peripheral sites, ${ }^{[1,2]}$ including the ulnar, musculocutaneous, supratrochlear, and infraorbital nerves, for minor surgical procedures in the 1880s. James Leonard Corning recommended the use of an Esmarch bandage in 1885 to arrest the local circulation, ${ }^{[3]}$ prolong the cocaine-induced block, and decrease uptake of local anesthetic from tissues. This concept was furthered by Heinrich F. W. Braun, ${ }^{[4]}$ who substituted epinephrine, a "chemical tourniquet," in 1903. Braun also introduced the term conduction anesthesia in his 1914 textbook on local anesthesia, ${ }^{[5]}$ which described techniques for every region of the body. In 1920, the French surgeon Gaston Labat was invited by Charles Mayo to teach innovative methods of regional anesthesia at the Mayo Clinic. During his appointment there, Labat authored Regional Anesthesia: Its Technic and Application. ${ }^{[6]}$ The book was considered to be the definitive text on regional anesthesia for at least 30 years after its publication. Labat's textbook focused on the management of patients undergoing intra-abdominal, head and neck, and extremity procedures under infiltration, peripheral, plexus, and splanchnic blockade; neuraxial techniques were not widely applied at the time. Recently regional anesthesia has been developed with the available technology. The improvement of the nervous location through an electrical current has allowed knowing the different motor responses from peripheral nerves, and to offer to anesthetic procedures and analgesics insurances, reliablity and effectiveness. The neurostimulation has been a technique of nervous location based on the anatomy. ${ }^{[7]}$ A major publication in this story is that of Hadzic et al. ${ }^{[10]}$ who tells us about the characteristics and lack of refinement of the current neurostimulators. There was no needles of atraumatic design and high levels of current was required to produce a stimulation of motor response when this technology appeared. Stimulation of motor activity was not very specific and the needle tip to the proximity of the nerve could be quite distant and the unsuccessful block was 
common. But this has changed and developed with the advent of more refined, focused and sophisticated technology. Regional anesthesia, in developing countries, has been conducted under the real economy framework that these techniques developed with no alternative in the absence of other resources. Now, however, regional anesthesia has taken other paths. We stand at the door of a new era; neurostimulation or selective location of peripheral nerves and there is no return. ${ }^{[7]}$

Successful regional anesthesia of the upper extremity requires knowledge of brachial plexus anatomy from its origin, where the nerves emerge from the intervertebral foramina, to its termination as the peripheral nerves. Brachial plexus is a somatic nerve plexus formed by intercommunications among the ventral rami of the lower four cervical nerves (C5- C8) and the first thoracic nerve (T1). The plexus is responsible for the motor innervation to all of the muscles of the upper limb with the exception of the trapezius and levator scapula. Brachial plexus communicates with the sympathetic trunk by gray rami communicates that join all the roots of the plexus and are derived from the middle and inferior cervical sympathetic ganglia and the first thoracic sympathetic ganglion. ${ }^{[9]}$

The aim of our study is to compare brachial plexus block performed by the Axillary and the Coracoid infraclavicular routes using a peripheral nerve stimulator as regard block performance time, onset of sensory block, motor block intensity, block duration and success and failure rates.

\section{Subjects and Methods}

This study was carried out in the Department of Anaeshtesiology, Sri Shankaracharya Medical College and hospital, Bhilai, Durg, Chhattisgarh, over 40 adult patients of both sex in the period of six months march 2019 to September 2019. All patients were scheduled for elective surgery of the hand, wrist, or forearm. Informed written consent was obtained from every included patient.

Patients with diseases affecting sensory or motor functions of the upper extremity, pregnant woman, patients with allergy to local anesthetics and uncooperative patients were excluded from the study.

Preparation: Upon arrival in the operating room a wide bore I.V. cannula was inserted and infusion of I.V. fluids was started, blood pressure cuff and a pulse oximetry probe were attached to the non-involved arm and 3 ECG electrodes over the patient's chest. An electrode was placed over the patient's acromion and connected to the positive lead (anode) of the nerve stimulator.

Premedication: All patients received intravenous fentanyl in a dose of $1 \mu \mathrm{g} / \mathrm{kg} 5 \mathrm{~min}$ before the block performance. Patients were assigned to one of the following two groups (20 patients each):

* Group 1: infraclavicular coracoid approach.

* Group 2: Axillary approach.

For local anesthetia a mixture of equal parts of $0.5 \%$ bupivacaine and $2 \%$ lidocaine was used with a total volume of $40 \mathrm{ml}$ was used.

All blocks were done using a nerve stimulator and an insulated needle $(50 \mathrm{~mm}$ and 22-gauge). The stimulating current set to $1.5 \mathrm{~mA}$ and the stimulus frequency to $1 \mathrm{~Hz}$ and the impulse duration to $0.1 \mathrm{~ms}$.

The needle insertion site was identified $1 \mathrm{~cm}$ medial and 1 $\mathrm{cm}$ caudal to the cracoid process and marked by a pen and infiltrated with local anesthetic using a 25 -gauge needle. The local anesthetic was infiltrated a bit deeper into the pectoralis muscle to decrease the discomfort during needle insertion as well as soreness after the completion of the block procedure. Needle insertion: A 10-cm long, 22-gauge insulated needle, was attached to the negative lead (cathode) of the nerve stimulator and inserted directly perpendicularly to the skin and advanced until motor responses were observed in the muscles supplied by one of the four nerves (median, musculocutaneous, radial or ulnar) in synchrony with the stimuli The stimulating current was set to $1.5 \mathrm{~mA}$, the stimulus frequency to $1 \mathrm{~Hz}$ and the impulse duration to 0.1 ms. The current was gradually decreased, while the needletip approached the stimulated nerve. The needle is withdrawn subcutaneously and re-inserted more cephalad or more caudal until a motor response from the muscles supplied by another nerve was obtained. Satisfactory positioning of the needle was obtained when stimulation by $0.3-0.5 \mathrm{~mA}$ elicited visible muscle contractions in the muscles supplying each nerve.

A local twitch of the pectoralis muscle was typically elicited as the needle advanced beyond the subcutanous tissue. Once the pectoralis twitches disappear, the needle advancement should be slow while looking for the twitches of the brachial plexus.

Satisfactory positioning of the needle was obtained when stimulation by $0.3-0.5 \mathrm{~mA}$ elicited visible muscle contractions. Each of the two sites was injected with half of the selected dose of the local anesthetic material $(20 \mathrm{ml})$.

\section{Interpreting responses to nerve stimulation:}

- Pectoralis muscle - direct muscle stimulation- Arm adduction

- Latissimus dorsi - Arm adduction

- Axillary nerve - Deltoid muscle

- Musculocutaneous nerve - Biceps twitch

\section{(Group 2) Axillary Approach:}

Technique: After a thorough skin preparation, the pulse of the axillary artery was palpated high in the axilla. Once the pulse was felt, it was straddled between the index and the middle finger and firmly pressed against the humerus to prevent "rolling" of the axillary artery during block performance. The axillary artery was marked by a pen and the subcutaneous tissue overlying the artery was infiltrated with local anesthetic using a 25-gauge needle.

Needle insertion: A 10-cm long, 22-gauge insulated needle, attached to the negative lead (cathode) of the nerve stimulator and inserted above the axillary artery and advanced until motor responses from the median and the musculocutaneous nerves were consecutively obtained. The needle is withdrawn and reinserted below the artery until motor responses from the ulnar and radial nerves were obtained. Each of the four nerves is injected with 1/4th of the selected volume of the local anathetic material $(10 \mathrm{ml})$ after obtaining the maximum response by the stimulating current of $0.3-0.5 \mathrm{~mA}$. Injections were made slowly, while 
repeatedly aspirating the needle.

Measurements: The time to perform the block was defined as the time from the initial insertion of the needle to its removal.

The sensory onset time of the block was assessed in all the upper limb areas every 5 min until 30 min after the last injection; axillary nerve (lateral side of the upper arm), musculocutaneous nerve (lateral side of the forearm), radial nerve (dorsum of the hand over the 2nd metacarpophalangeal joint), median nerve (thenar eminence), ulnar nerve (little finger), medial cutaneous nerves of the arm (medial side of the upper arm) and of the forearm (medial side of the forearm).

Motor block was assessed every 5 min until $30 \mathrm{~min}$ for 4 motor nerves the radial (thumb abduction), median (third finger flexion), ulnar (fifth finger flexion), musculocutaneous (elbow flexion), and axillary (arm abduction) nerves and then compared to the contralateral arm. Motor block was scored
$0=$ no motor block; $1=$ minor movements $; 2=$ no movement.

Adverse effects were recorded (e.g) occurrence of local anesthetic toxicity, nausea or vomiting. Duration of the block and success and failure rates was recorded.

Statistical presentation and analysis of the present study was conducted, using the mean, standard deviation (student's ' $t$ ' test), and chi-square test by SPSS V.16.

\section{Results}

The present study was carried out on 40 patients scheduled for surgery on the upper limb (forearm or hand).

Patients were classified into two groups:

*Group (1): Infraclavicular coracoid approach.

*Group (2): Axillary approach.

Each of the two groups contains 20 patients.

Table 1: Patients' demographic data

\begin{tabular}{|c|c|c|c|c|c|c|}
\hline \multirow[t]{2}{*}{ NO. } & \multicolumn{2}{|l|}{ Age } & \multicolumn{2}{|l|}{ Wt. } & \multicolumn{2}{|l|}{ Sex } \\
\hline & Coracoid group & Axillary group & Coracoid group & Axillary group & Coracoid group & Axillary group \\
\hline Range & $22-69$ & $21-70$ & $60-80$ & $58-86$ & $\mathrm{M}=17$ & $\mathrm{M}=15$ \\
\hline Mean + SD & $37.60+12.22$ & $38.30+14.20$ & $70.25+5.74$ & $70.60+6.34$ & $\mathrm{~F}=3$ & $\mathrm{~F}=5$ \\
\hline t. test & \multicolumn{2}{|l|}{0.167} & \multicolumn{2}{|l|}{0.183} & \multicolumn{2}{|l|}{0.625} \\
\hline p. value & 0.868 & & 0.856 & & 0.429 & \\
\hline
\end{tabular}

As seen in [Table 1], there was no much diference in the age, weight of the patients of both groups, which was statistically non significant $(\mathrm{P}-$ value $=0.868)$. The male to female ratio in the coracoid group was 17:3 (85\% males and $15 \%$ females) while in the axillary group the ratio was $15: 5$ (75\% males and $25 \%$ females $)(P$ - value $=0.429)$.

Table 2: Comparison between coracoid and axillary groups as
regard block performance time in both groups
\begin{tabular}{|l|l|l|}
\hline $\begin{array}{l}\text { Block performance } \\
\text { time (minutes) }\end{array}$ & $\begin{array}{l}\text { Coracoid } \\
\text { group }\end{array}$ & $\begin{array}{l}\text { Axillary } \\
\text { group }\end{array}$ \\
\hline Range & $3-8$ & $3-8$ \\
\hline Mean + SD & $5.86+1.30$ & $5.80+1.39$ \\
\hline t. test & 0.658 & \\
\hline P. value & 0.963 & \\
\hline
\end{tabular}

Above table showed that there was no statistically significant difference in the time needed to perform the block in both group $(\mathrm{P}$ - value $=0.963)$.

Table 3: Comparison between coracoid and axillary groups as
regard sensory onset time in both groups
\begin{tabular}{|l|l|l|}
\hline $\begin{array}{l}\text { Sensory onset } \\
\text { time in minutes }\end{array}$ & $\begin{array}{l}\text { Coracoid } \\
\text { group }\end{array}$ & $\begin{array}{l}\text { Axillary } \\
\text { group }\end{array}$ \\
\hline Range & $25-35$ & $16-22$ \\
\hline Mean + SD & $30+3.61$ & $19.05+1.93$ \\
\hline t. test & 11.952 & \\
\hline P. value & $0.001^{*}$ & \\
\hline
\end{tabular}

The results were statistically significant. So, patients of the axillary group were sooner ready for surgery than patients of the coracoid group. $(\mathrm{P}$-value $=0.001)$

Table 4: Comparison between coracoid and axillary groups as regard the intensity of motor block after 30 minutes in both groups

\begin{tabular}{|l|l|l|l|l|l|}
\hline & Good & Satisfactory & Poor & Total \\
\hline Coracoid & $\%$ & 30 & 50 & 20 & 100 \\
\hline Axillary & $\%$ & 75 & 20 & 5 & 100 \\
\hline P-value & $0.016^{*}$ & \\
\hline
\end{tabular}

As demonstrated in [Table 4], motor block was assessed every $5 \mathrm{~min}$ from the end of the block until $30 \mathrm{~min}$ in the distribution of the motor nerves. Motor block was scored: $0=$ poor block, $1=$ satisfactory block, $2=$ good block.

Motor block was significantly more intense in the axillary group than the coracoid group and resulted in a better quality of motor block. (P-value=0.016).

Table 5: Comparison between coracoid and axillary groups as regard the total block duration (in minutes) in both groups

\begin{tabular}{|l|l|l|}
\hline $\begin{array}{l}\text { Block } \\
\text { duration } \\
\text { (min)s }\end{array}$ & Coracoid & Axillary \\
\hline Range & $35-60$ & $40-81$ \\
\hline Mean + SD & $48.50+8.53$ & $58.15+1.60$ \\
\hline t. test & 2.836 & \\
\hline p. value & $0.002^{*}$ & \\
\hline
\end{tabular}

As demonestated in [Table 5], the duration was significantly longer in the axillary group. This allows for a longer duration of surgery and longer duration of post-operative analgesia in patients of the axillary group than patients of the coracoid group $(\mathrm{P}$ - value $=0.002)$.

\begin{tabular}{|l|l|l|l|l|l|}
\hline Table 6: Side effects and complications in both groups \\
\hline & Coracoid & $\%$ & Axillary & \% & p.value \\
\hline $\begin{array}{l}\text { Vascular } \\
\text { puncture }\end{array}$ & 1 & 5 & 3 & 15 & $0.041^{*}$ \\
\hline $\begin{array}{l}\text { Tourniquet } \\
\text { pain }\end{array}$ & 1 & 5 & 4 & 20 & $0.039^{*}$ \\
\hline $\begin{array}{l}\text { Muscle pain } \\
\text { at injection } \\
\text { site }\end{array}$ & 2 & 10 & 0 & 0 & $0.001^{*}$ \\
\hline
\end{tabular}




\begin{tabular}{|l|l|l|l|l|l|}
\hline $\begin{array}{l}\text { Other } \\
\text { symptoms }\end{array}$ & 0 & 0 & 0 & 0 & -- \\
\hline
\end{tabular}

Vascular puncture and hematomas were observed in two patients in the axillary group after performance of the block and they did not require treatment $(\mathrm{P}$-value $=0.041)$. Tourniquet pain was reported by one patient in the coracoid group and four patients in the axillary group ( $\mathrm{P}$-value $=$ 0.039). Muscle pain at the site of injection occurred in two cases of the coracoid group $(\mathrm{P}$-value $=0.001)$.

Table 7: Success rate of both approaches

\begin{tabular}{|l|l|l|}
\hline No. & Coracoid & Axillary \\
\hline$\%$ & $60 \%$ & $85 \%$ \\
\hline Chi-square & 3.097 \\
\hline P.value & $0.049 *$ \\
\hline
\end{tabular}

As shown in [Table 7], axillary block was significantly more successful than the coracoid block and resulted in more complete blocks ( $85 \%$ of cases) than the coracoid block $(60 \%$ of cases $)(\mathrm{P}-\mathrm{value}=0.049)$.

\section{Discussion}

As ambulatory surgery continues to grow, more invasive and painful surgeries are being performed. The challenge for ambulatory anesthesiologists is to provide anesthesia that achieves home readiness within hours of surgery concurrent with prolonged postoperative analgesia. The use of rapid acting anesthetics has facilitated the efficient discharge of an alert outpatient. $^{[30]}$

Peripheral nerve blocks (PNBs) possess many characteristics of the ideal outpatient anesthetic. They provide site-specific surgical anesthesia and minimize the need for general anesthesia (GA). By providing dense analgesia, opioid requirements are reduced as well as opioid-related side effects. A comfortable, symptom free patient can be discharged home in a timely fashion. ${ }^{[31]}$

Regional anesthesia for upper limb surgery can be performed by brachial plexus block via several approaches.14 Perivascular axillary brachial plexus block is a popular technique owing to its low complication rate and ease of performance. This technique can provide good surgical conditions at the hand, forearm and arm. ${ }^{[31,32]}$

The coracoid infraclavicular block is performed at the level of the divisions and cords of the brachial plexus where they envelope the subclavian artery. ${ }^{[33,34]}$ The coracoid infraclavicular brachial plexus block is a relatively new technique for which the coracoid process is the anatomic point. With this approach, it is possible to cover all sensory territories of the distal part of upper limb. ${ }^{[35,36]}$

The terminal nerves of the brachial plexus are contained with the axillary artery in a common sheath. ${ }^{[37]}$ The artery is easily palpable and serves as a useful landmark for the axillary block. The axillary approach to the brachial plexus block has a great popularity in providing anesthesia for hand and forearm surgery. The procedure is relatively safe and if dosage limits are adjusted, complications are uncommon. ${ }^{[31,38]}$

The axillary approach is a relatively simple technique with a low incidence of complications, no effect on the phrenic nerve, and an extremely low risk of pneumothorax. ${ }^{[31]}$ It usually provides good anesthesia and analgesia for procedures distal to the elbow However, its application may be difficult in patients with limited movement of the shoulder or arm, as in those with painful injury. ${ }^{[33,36]}$

In our study we compare brachial plexus block performed by the axillary and the coracoid infraclaviular routes using a peripheral nerve stimulator as regard block performance time, onset of sensory block, motor block intensity, block duration and success rate.

The result of the present study is the finding that the axillary approach to the brachial plexus using four injections of the local anesthetic material resulted in a faster onset and fewer incomplete blocks than the coracoid approach using two injections. The axillary approach was also less painful and more comfortable to the patient with little side effects.

The coracoid approach had the following advantages over the axillary: the coracoid approach can be done with the arm in the neutral position, which is important for patients with an arthritic or stiff shoulder joint, and the coracoid process is easily palpable even in obese patients. The local anaesthetic is injected above the head of the humerus, avoiding the limitations reported in axillary block and ensures proximal spread of local anaesthetic. ${ }^{[39]}$

However, our results indicate that injection at the cord level using the coracoid approach did not improve block effectiveness. In spite of the use of a double injection technique; only $60 \%$ of patients in the coracoid group had complete analgesia distal to the elbow, compared with $85 \%$ in the axillary group using a quadraple injection technique.

The relationship between number of injections and block effectiveness is in concordance with a study of Bouaziz et al. ${ }^{[28]}$ who obtained $54 \%$ success after double injection axillary block and $88 \%$ after quadruple injection midhumeral block, and with the study of Koscielniak-Nielsen 11 in which double injection resulted in $62 \%$ and quadruple injection in $88 \%$ success.

The low effectiveness of the coracoid approach may be explained by insufficient spread of a local anaesthetic to the medial cord, from which the ulnar and the medial cutaneous nerves arise. Thompson and Rorie showed that the axillary neurovascular sheath is divided by connective tissue septae ${ }^{[19]}$ which limit diffusion of local anaesthetic to the terminal nerves. Results of our study indicate that similar septa may also exist at the cord level, and the double injection technique is not enough to ensure a high success rate. ${ }^{[19]}$

One may argue that the volume of the local anesthetic material used in our study $(40 \mathrm{ml})$ was insufficient to ensure spread to the three cords. Whiffler, ${ }^{[39]}$ reported $93 \%$ success using up to $60 \mathrm{ml}$ of local anaesthetic. On the other hand, Raj et al. ${ }^{[34]}$ had over $95 \%$ success using $20-30 \mathrm{ml}$. As much as $80 \mathrm{ml}$ injected at one site into the axillary neurovascular sheath resulted in only $54 \%$ success. ${ }^{[41]}$ These contradictory results indicate that the volume of local anaesthetic is not a major determinant of success.

In our study, we observed that the block performance time did not differ between the two groups, ranged in both groups (3-8 minutes), despite double the number of nerves stimulated in the axillary group (four nerve stimulations) compared with double nerve stimulations in the coracoid group, and was similar to other studies of axillary block 
using multiple electrolocations. ${ }^{[23,42]}$ This may be explained by the deeper position of the cords in the coracoid block. In another study, Koscielniak-Nielsen, ${ }^{[1]}$ compared the coracoid infraclavicular and axillary techniques with the use of peripheral nerve stimulator and did not find a difference in terms of the duration of performance of the block between the groups.

Our results show that, shorter block latency in the axillary group was partly caused by the more uniform analgesia below the elbow. Therefore, the total time to complete block was shorter using axillary rather than coracoid approach and the readiness for surgery was faster with the axillary approach than with the coracoid approach. Whiffler39 also had obtained similar results and concluded that the thick axillary sheath was probably responsible for this effect. ${ }^{[29]}$ In contrast, Kilka, ${ }^{[33]}$ observed a rapid onset time (median of $13.5 \mathrm{~min}$ ) following infraclavicular brachial plexus block and in agreement with the study of Sims, who noticed an onset time of 15 min. ${ }^{[43]}$

In our study motor block was significantly more intense in the axillary group than the coracoid group and resulted in a better quality of motor block. In the study of kilka, ${ }^{[33]}$ who compared axillary and infraclavicular approaches, the motor block was not significantly different between the two groups. In our study, the duration was significantly longer in the axillary group than the coracoid group. This allows for a longer duration of surgery and longer duration of postoperative analgesia in patients of the axillary group than patients of the coracoid group. In the study of kilka, ${ }^{[33]}$ who compared axillary and infraclavicular approaches, the duration of sensory block was not significantly different between the two groups. Also the study of Kapral, ${ }^{[45]}$ who compared axillary and infraclavicular approaches, the duration of sensory block was not significantly different between the two groups.

In our study, the incidence of vascular puncture was more in the axillary group (four patients) than the coracoid group (one patient). The anatomical study by Wilson, ${ }^{[43]}$ demonstrated that the posterior cord lies dorsal to the subclavian artery, which is therefore in the path of a needle in the coracoid approach and can predispose to vascular injury. This point may have important consequences considering that the intravenous administration of local anesthetics may potentially increase the risk of systemic toxicity. Whiffler, ${ }^{[39]}$ did not observe any haematomas despite a 50\% incidence of arterial puncture during coracoid block. Haematomas, which developed immediately after block performance and were seen as swelling and discolouration of the puncture site. Although neither patients nor surgeons were disturbed by them, the inability to compress the source of bleeding is a disadvantage of the coracoid approach.

In our study, the coracoid group patients experienced significantly more pain during block performance than axillary group. Patients mostly reacted during subcutaneous infiltration and subsequent needle insertions. Only a few patients described the electrical stimulation as painful.

Infraclavicular approach to the brachial plexus had a number of advantages: the block can be performed with the arm on the side or abducted, and it is unlikely to accidentally puncture central neuroaxial structures or pleura. In the study of Kilka, ${ }^{[33]}$ the complications related to infraclavicular brachial plexus block were venous puncture and temporary Horner's syndrome. They did not observe arterial puncture or pneumothorax. In the study of Salazar, ${ }^{[15]}$ it was reported that the infraclavicular technique was more effective and had a lower complication risk than the axillary technique. In our study, Horner syndrome or pneumothorax did not develop in any of the patients.

Symptoms of systemic toxicity from local anesthetic agents didn't occur in any of patients of the two groups. The studies by both Stan, ${ }^{[24]}$ and Koscielniak-Nielsen40 they reported that the symptoms of intra-arterial injection were transient and disappeared without sequelae.

Only few studies have compared the coracoid infraclavicular approach with the axillary approach for brachial plexus block. Kapral et al. ${ }^{[45]}$ compared the two techniques in their study and showed that it was easier to obtain motor and sensory block on the musculocutaneous nerve area by the infraclavicular technique. They also demonstrated that it was easier to obtain block of the thoracodorsal, axillary and median nerves by the infraclavicular approach compared with the axillary approach. ${ }^{[45]}$

In the study of Kapral, ${ }^{[45]}$ the success rates of the infraclavicular and axillary approaches were $100 \%$ and $85 \%$, respectively. In contrast, technical success rates in our study were $60 \%$ for the infraclavicular block and $85 \%$ for the axillary block.

\section{Conclusion}

Peripheral nerve blocks (PNBs) have an increasingly important role in ambulatory anesthesia and have many characteristics of the ideal outpatient surgical anesthesia with prolonged postoperative analgesia, and facilitated discharge. The result of our study showed that the axillary approach to the brachial plexus using four injections of the local anesthetic material resulted in a faster onset and fewer incomplete blocks than the coracoid approach using two injections. The axillary approach was also less painful and more comfortable to the patient and resulted in more intense motor block and provided a longer duration of block allowing for longer duration of anesthesia and postoperative analgesia, symptoms of systemic toxicity from local anesthetic agents didn't occur in any of patients of the two groups. The coracoid approach had an advantage over the axillary that it can be done with the arm in the neutral position, which is important for patients with an arthritic or stiff shoulder joint.

So we conclude that the axillary approach to the brachial plexus using four injections technique resulted in a faster onset of block and a better spread of analgesia and longer duration of anesthesia than the coracoid approach using two injections technique.

\section{References}

1. Hall RJ: Hydrochlorate of cocaine. N Y Med J 1884; 40:643.

2. Halsted WS: Practical comments on the use and abuse of cocaine: Suggested by its invariably successful employment in more than a thousand minor surgical operations. N Y Med J 1885; 42:294.

3. Corning JL: On the prolongation of the anesthetic effect of the 
hydrochlorate of cocaine, when subcutaneously injected: An experimental study. N Y Med J 1885; 42:317.

4. Braun H: Ueber den Einfluss der Vitalitat der Gewebe auf die ortlichen und allgemeinen Giftwirkungen local anasthesirender Mittel und uber die Bedeutung des Adrenalins fur die local anasthesie. Arch Klin Chir $1903 ; 69: 541$

5. Braun H: Local Anesthesia: Its Scientific Basis and Practical Use. 3rd ed. Philadelphia, Lea and Febiger, 1914

6. Labat G: Regional Anesthesia: Its Technic and Clinical Application. Philadelphia, WB Saunders, 1922

7. G. Zaragoza-Lemus,et.al. : Neurostimulation and peripheral nerve block in regional Anesthesia. Revista Mexicana de Anestesiología. Vol. 31. No. 2 April-June 2008

8. Hadzic A, Vloka J, Thys D, Santos A. Nerve stimulators used for peripheral nerve blocks vary in their electrical characteristics. Anesthesiology 2003; 98: 969-74

9. H. Ellis, S. Feldman and W. Harrop- Griffith: Anatomy of the brachial plexus. Anatomy for anaesthetists 8th Edition. Blackwell publishing; USA; $2003 ; 153-79$.

10. Desroches J. The infraclavicular brachial plexus block by the coracoid approach is clinically effective: an observational study 150 patients. Can J Anaesth 2003; 50: 253- 257.

11. Koscielniak- Nielsen. A comparison of coracoid and axillary approaches to the brachial plexus . Acta Anaesth Scand 2000; 44: 274- 9.

12. Rodrıguez J, Ba ŕrcena M, Rodrı́guez V, et al. Infraclavicular brachial plexus block: effects on respiratory function and extent of the blockade. Reg Anesth Pain Med. 1998; 23: 564- 8

13. Delgado TJ. Bloqueo infraclavicular del plexo braquial con técnica de inyección múltiple y abordaje en sentido craneal en pacientes con dificultad prevista de intubación traqueal. Rev Soc Esp de Dolor. 2002; 49; $105-107$.

14. Borgeat A, Ekatodramis G. An evaluation of the infraclavicular block via a modified approach of the Raj technique. Anesth Analg. 2001; 93: 436- 441 .

15. Salazar $\mathrm{CH}$, Espinosa W. Infraclavicular brachial plexus block: variation in approach and results in 360 cases. Reg Anesth Pain Med 1999; 24: 411- 416

16. Schroeder LE, Horlocker TT, Schroeder DR: The efficacy of axillary block for surgical procedures about the elbow. Anesth Analg 1996; 83:747

17. Serlo W, Haapanemi L: Regional anaesthesia in paediatric surgery. Acta Anaesthesiol Scand $1985 ; 29: 283$

18. Neal JM, Hebl JR, Gerancher JC, Hogan QH. Brachial plexus anesthesia: Essential of our current understanding. Reg Anesth Pain Med 2002;4:402-428

19. Thompson GE, Rorie DK. Functional anatomy of the brachial plexus sheats. Anesthesiology 1983;59:117-122.

20. Klein SM, Pietrovon R, Nielsen KC. Peripheral nerve blockade with long-acting local anesthetics: Survey of the Society for Ambulatory Anesthesia. Anesth Analg 2002:94:71-76.

21. Bouaziz H, Narchi P, Mercier FJ, Khoury A, Poirier T, Benhamou D. The use of selective axillary nerve block for outpatient hand surgery. Anesth Analg 1998;86:746-748.

22. Thompson GE, Rorie DK. Functional anatomy of the brachial plexus sheats. Anesthesiology 1983;59:117.

23. Koscielniak-Nielsen ZJ, Hesselbjerg L, Fejlberg V.Comparison of transarterial and multiple nervestimulation techniques for an initial axillary block by $45 \mathrm{~mL}$ of mepivacaine $1 \%$ with adrenaline. Acta Anaesthesiol Scand 1998;42:570-575.

24. Stan TC, Krantz MA, Solomon DL, Poulos JG, Chaouki K. The incidence of neurovascular complications following axillary brachial plexus block using a transarterial approach. Reg Anesth 1995;20:486492.

Copyright: (C) the author(s), publisher. Academia Anesthesiologica International is an Official Publication of "Society for Health Care \& Research Development". It is an open-access article distributed under the terms of the Creative Commons Attribution Non-Commercial License, which permits unrestricted non-commercial use, distribution, and reproduction in any medium, provided the original work is properly cited.

How to cite this article: Akhtar P, Dasgupta S, Rangari P. Brachial Plexus Block For Upper Limb Surgery Coracoid Infraclavicular Approach versus Axillary Approach- A Comparitive Study. Acad. Anesthesiol. Int. 2019;4(2):244-9.

DOI: dx.doi.org/10.21276/aan.2019.4.2.55

Source of Support: Nil, Conflict of Interest: None declared.
25. Ababou A, Marzouk N, Mosadiq A, Sbihi A: The effects of arm position on onset and duration of axillary brachial plexus block. Anesth Analg 2007; 104:980.

26. Selander D, Edshage S, Wolff T: Paresthesia or no paresthesia. Acta Anaesthesiol Scand 1979; 23:27.

27. Cooper K, Kelley H, Carrithers J. Perceptions of side effects following axillary block used for outpatient surgery. RegAnesth 1995;20:212-6.

8. Bouaziz H, Carchi P, Mercier FJ, Labaille T, Zerrouk N, Girod J, Benhamou D. comparison between conventional axillary block and a new approach the midhumeral level. Anesth Analg 1997;84:1058-1062.

29. Pere P, Pitkanen M, Rosenberg PH, Bjorkenheim J-M, Linden H, Salorinne Y, Tuominen M. Effect of continuous interscalene brachial plexus block on diaphragm motion and on ventilatory function. Acta Anaesthesiol Scand 1992;36:53-57.

30. Baranowski AP, Pither CE. A comparison of three methods of axillary brachial plexus. Anaesthesia 1990; 45:362 - 5.

31. Hill DA, Campbell WI. Two approaches to the axillary brachial plexus. Loss of resistance to saline or paraesthesia? Anaesthesia 1992; 47: $207-9$.

32. Jandard C, Gentili ME, Girard F, et al. Infraclavicular block with lateral approach and nerve stimulation: extent of anesthesia and adverse effects. Reg Anesth Pain Med 2002;27:37-42.

33. Kilka HG, Geiger P, Mehrkens HH. Infraclavicular vertical brachial plexus blockade: a new method for anesthesia of the upper extremity. An anatomical and clinical study Anaesthesist 1995; 44:339-44.

34. Raj PP, Montgomery SJ, Nettles D, Jenkins MT. Infraclavicular brachial plexus block- a new approach. Anesth Analg 1973; 52: 897-904.

35. Brown DL, Bridenbaugh LD. The upper extremity: somatic block in neural block. In: Cousins JM, Bridenbaugh OP, eds. Neural Blockade, 4th edn. Philadelphia, Toronto: JB Lippincott Company, 1998: 345-73.

36. Partridge BL, Katz J, Benirschke K. Functional anatomy of the brachial plexus sheath: implications for anesthesia. Anesthesiology 1987;66:743-7.

37. Hadzic A, Vloka JD, Kuroda MM, et al. The practice of peripheral nerve blocks in the United States: a national survey. Reg Anesth Pain Med 1998;23:241-6.

38. Winnie AP, Radonjic R, Akkineni SR, Durrani Z. Factors influencing distribution of local anesthetic injected into the brachial plexus sheat. Anesth Analg 1979: 58: 225-234.

39. Whiffler K. Coracoid block - a safe and easy technique. Br J Anaesth 1981: 53: 845-848.

40. Koscielniak-Nielsen ZJ, Rotbøll Nielsen P, Sørensen T, StenørM. Low dose axillary block by targeted injections of the Terminal nerves. Can J Anaesth 1999: 46: 658-664.

41. Koscielniak-Nielsen ZJ, Stens-Pedersen HL, Knudsen Lippert F. Readiness for surgery after axillary block: Single or multiple injection techniques. Eur J Anaesthesiol 1997: 14: 164-171.

42. Sims JK. A modification of landmarks for infraclavicular approach to brachial plexus block. Anesth Analg 1977: 56: 554-555.

43. Wilson JL, Brown DL, Wong GY, Ehman RL, Cahill DR. the coracoid technique. Anesth Analg 1998: 87:870-873.

44. Fanelli G, Casati A, Garancini P, Torri G. Nerve stimulator and multiple injection technique for upper and lower limb blockade: failure rate, patient acceptance, and neurologic complications. Study Group on Regional Anesthesia. Anesth Analg 1999; 88: 847-52.

45. Kapral S, Jandrasits O, Schabernig C et al. Lateral infraclavicular plexus block vs. axillary block for hand and forearm surgery. Acta Anaesthesiol Scand 1999; 43: 1047-52.

46. Fleischmann E, Marhofer P, Greher M, Waltl B, Sitzwohl C, Kapral S. Brachial plexus anaesthesia in children: lateral infraclavicular vs Infraclavicular brachial plexus block: Parasaggital anatomy important to axillary approach. Paediatr Anaesth 2003; 13: 103-8. 